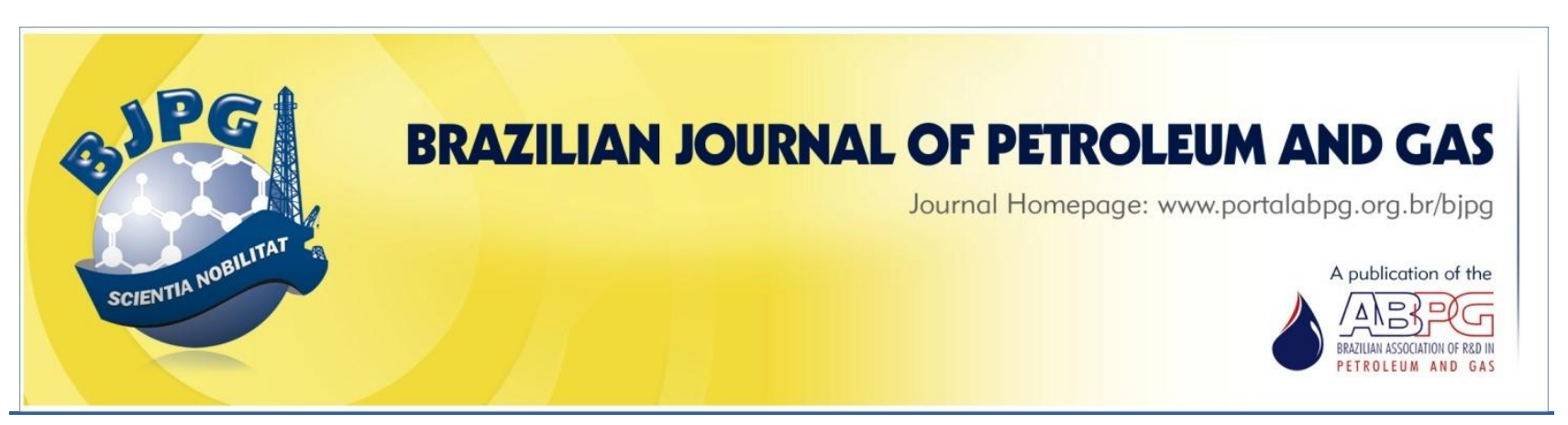

\title{
AN INVESTIGATION ON THE USE OF SURFACTANTS IN THE ORGANOPHILIZATION OF BENTONITE CLAY FOR OIL-BASED DRILLING FLUIDS
}

\author{
${ }^{\text {a }}$ Silva, R. P. ${ }^{1}$; ${ }^{\text {a }}$ Santanna, V. C.; ${ }^{\text {a }}$ Barillas, J. L. M.; ${ }^{\text {a }}$ Castro Dantas, T. N. \\ ${ }^{a}$ Department of Petroleum Engineering, Federal University of Rio Grande do Norte - RN - Brazil \\ Received: 19.12.2016 / Revised: 23.02.2017 / Accepted: 02.03.2017 / Published on line: 23.03.2017
}

\begin{abstract}
Due to the challenges encountered in well drilling operations, there are continuous demands for the development of fluids with specific physical-chemical and rheological properties. Such fluids must be controlled carefully to meet all technical criteria established. In drilling operations carried out offshore and in water-sensitive formations, oil-based drilling fluids must be used. Bentonite clay can be employed in such operations, after a previous surface treatment is undertaken, to render it hydrophobic. In this work, calcic bentonite clay was modified with the purpose of enhancing its affinity for the organic phase in oil-based drilling fluids. Three different surfactants, namely, saponified coconut oil (SCO), hexadecyltrimethyl ammonium bromide (CTAB), and a nonionic ethoxylated amine (UTM 150) were examined at different concentrations. The results indicate that UTM 150 and CTAB are more efficient in the organophilization of the clay, which can then be added in the compositions of oil-based drilling fluids that are potential candidates for real applications.
\end{abstract}

\section{KEYWORDS}

surface modification; organophilic clay; drilling fluid; surfactant; bentonite

\footnotetext{
${ }^{1}$ To whom all correspondence should be addressed.

Address: Department of Petroleum Engineering, Federal University of Rio Grande do Norte - RN - Brazil.

ZIP Code: 59072-970 | Telephone: +55 84 99607-6728 |e-mail: rhaul @ hotmail.com

doi:10.5419/bjpg2017-0004
} 


\section{INTRODUCTION}

Bentonite clays have been used for many years as dispersed agents in the composition of waterbased drilling fluids, with several functions during the entire process (Caenn \& Chillingar, 1996).

The petroleum industry is one of the main markets for bentonite clay. It uses the clay as a thixotropic agent in oil-well drilling fluids. As part of the fluid, the clay confers some important physical-chemical characteristics to it. These characteristics must be controlled carefully so that the fluid may exert all its functions with good performance. Fluid functions include cooling of the drills, generation of a low-permeability layer on the geological formation, and maintenance of solids in suspension (Caenn \& Chillingar, 1996).

In offshore and water-sensitive drilling operations, normally it is necessary to use oil-based fluids (Bourgoyne et al., 1991; Melton et al., 2003). In such cases, bentonitic clays lose their thixotropic properties and therefore cannot be used without a previous organic treatment to render their surfaces hydrophobic, since their natural state is hydrophilic (Silva et al., 2014).

Sánchez-Martín et al. (2008) examined the adsorption of three distinct surfactants, namely, the nonionic Triton X-100 (TX100), the anionic sodium dodecylsulfate (SDS), and the cationic octadecyltrimethyl ammonium bromide (ODTMA) in different types of clay. They observed that the adsorption of SDS and ODTMA was favored in all types of clay up to the critical micelle concentration (c.m.c.) of the surfactants. However, the adsorption of TX100 was much more intense when its concentration was much higher than the c.m.c.

Ouellet-Plamondon et al. (2013) investigated the modification of bentonite by varying the concentration of hexadecyltrimethyl ammonium chloride (HDTMA), propylene glycol (PPG) 1200 and 2000, lecithin, and Topcithin ${ }^{\mathrm{TM}}$. The modification of the bentonite was characterized by X-ray diffraction (XRD), thermogravimetric analysis (TGA), Fourier-transform infrared spectroscopy (FTIR), and specific surface and porous volume. Three intercalation regions were identified depending on the surfactant. The nonionic surfactant caused only expansion on the crystalline arrangement of the bentonite layers, whilst the ionic surfactants caused osmotic intercalation. Also, the surfactant derived from lecithin could interact deeply with the bentonitic matrix.

Parolo et al. (2014) reported the organic modification of a natural bentonite by using two techniques: changing cations among the layers with HDTMA and incorporating vinyltrimethoxysilane (VTMS) or ?]methacryloxypropyltrimethoxysilane (TMSPMA) on the surface of montmorillonite. The physicalchemical characterization of these materials was carried out by XRD, TGA, IR spectroscopy, and Brunauer-Emmet-Teller (BET) surface area techniques. Hexadecyltrimethyl ammonium cations and organosilane groups were intercalated in the spaces among the montmorillonite layers, as indicated by the increase in the basal spacing. Specstrocopy, TGA, and BET data indicated that the organic modification was successful.

The main objective of this work is to investigate an effective procedure to chemically modify a bentonitic clay with the purpose of enhancing its affinity with organic components in oil-based drilling fluids, by using solutions of ionic and nonionic surfactants from their critical micelle concentrations (c.m.c.).

\section{MATERIALS AND METHODS}

Clay samples used in this study are calcic bentonites found in the State of Paraíba (PB, Brazil). Three surfactants were tested in the organophilization process: the anionic saponified coconut oil (SCO), the cationic hexadecyltrimethyl ammonium bromide (CTAB), and a nonionic ethoxylated amine (UTM 150), which is a tallow grease with 15 ethylene oxide units.

\subsection{Clay organophilization}

The organophilization of the clay samples was performed with solutions of each surfactant at the c.m.c. and concentrations $30 \%$ higher and $30 \%$ lower than the corresponding c.m.c., as shown in Table 1. Surface tension measurements were carried out previously for the surfactant solutions, at $25{ }^{\circ} \mathrm{C}$, by using the maximal bubble pressure methodology at air-water and air-solution interfaces. The clay was added to each solution so as to prepare $4.16 \%$ (mass/volume) mixtures. Each 
Table 1. Concentrations of surfactant used in organophilization.

\begin{tabular}{lc}
\hline \multicolumn{1}{c}{ Surfactant } & Concentration / (g/L) \\
\hline SCO 30\% higher than c.m.c. & 5.171 \\
SCO at c.m.c. & 3.978 \\
SCO 30\% lower than c.m.c. & 2.784 \\
CTAB 30\% higher than c.m.c. & 0.815 \\
CTAB at c.m.c & 0.627 \\
CTAB 30\% lower than c.m.c. & 0.439 \\
UTM 150 30\% higher than c.m.c. & 1.278 \\
UTM 150 at c.m.c & 0.983 \\
UTM 150 30\% lower than c.m.c. & 0.688 \\
\hline
\end{tabular}

Table 2. Surface tension of the filtrates after organophilization.

\begin{tabular}{lc}
\hline \multicolumn{1}{c}{ Surfactant solution } & Surface Tension / (dyn/cm) \\
\hline SCO 30\% higher than c.m.c. & 40.7 \\
SCO at c.m.c. & 47.1 \\
SCO 30\% lower than c.m.c. & 69.0 \\
CTAB 30\% higher than c.m.c. & 71.9 \\
CTAB at c.m.c & 71.9 \\
CTAB 30\% lower than c.m.c. & 71.9 \\
UTM 150 30\% higher than c.m.c. & 71.8 \\
UTM 150 at c.m.c & 71.9 \\
UTM 150 30\% lower than c.m.c. & 71.8 \\
\hline
\end{tabular}

system was stirred at $750 \mathrm{rpm}$ for 20 minutes at $80^{\circ} \mathrm{C}$. After this step, the mixtures were allowed to rest for 24 hours and, then, filtered out. The filtrates were reserved for subsequent surface tension analyses and the clay was allowed to dry in a laboratory oven for 48 hours at $60^{\circ} \mathrm{C}$.

\subsection{Analysis of filtrates}

Surface tension of the filtrates after clay organophilization was carried out with a SensaDyne Tensiometer, using the method of maximum bubble pressure at $25^{\circ} \mathrm{C}$.

\subsection{X-Ray diffraction}

Clay samples were analyzed by X-ray diffraction (XRD) in a Shimadzu XRD 6000 equipment. Copper $\mathrm{K}-\alpha$ radiation was used at $40 \mathrm{kV}$ and $30 \mathrm{~mA}$, with goniometer speed of $2^{\circ} / \mathrm{min}$ and $0.02^{\circ}$ steps. This assay is useful to determine the increase in the basal spacing among the clay layers in the presence of surfactant after the organophilization process.

\subsection{Contact angle}

Measurements of contact angle were carried out in a Kruss $\mathrm{K} 100 \mathrm{C}$ tensiometer. Sample tablets were made with both modified and original clays in a hydraulic press. For data acquisition, droplets of water and n-paraffin were deposited onto the tablets. The purpose of this assay is to determine the wettability of all clay samples.

\section{RESULTS AND DISCUSSION}

Data of surface tension of the filtrates obtained after the organophilization process are shown in Table 2.

It is known that the surface tension of pure water is approximately $72.1 \mathrm{dyn} / \mathrm{cm}$ at $25^{\circ} \mathrm{C}$. If the surface tension of a given solution is close to this value, it is highly probable that practically all surfactant molecules have been adsorbed by the clay in the organophilization process, and very little of it remains in the filtrate. In view of this, it is desired to use solutions with high surface tension, such as those prepared with UTM 150 and CTAB.

Figure 1 shows the XRD spectrum of the original clay sample before the organophilization process. It is possible to detect the presence of silicon dioxide at the interplanar distances of $33.3877 \AA$ and 


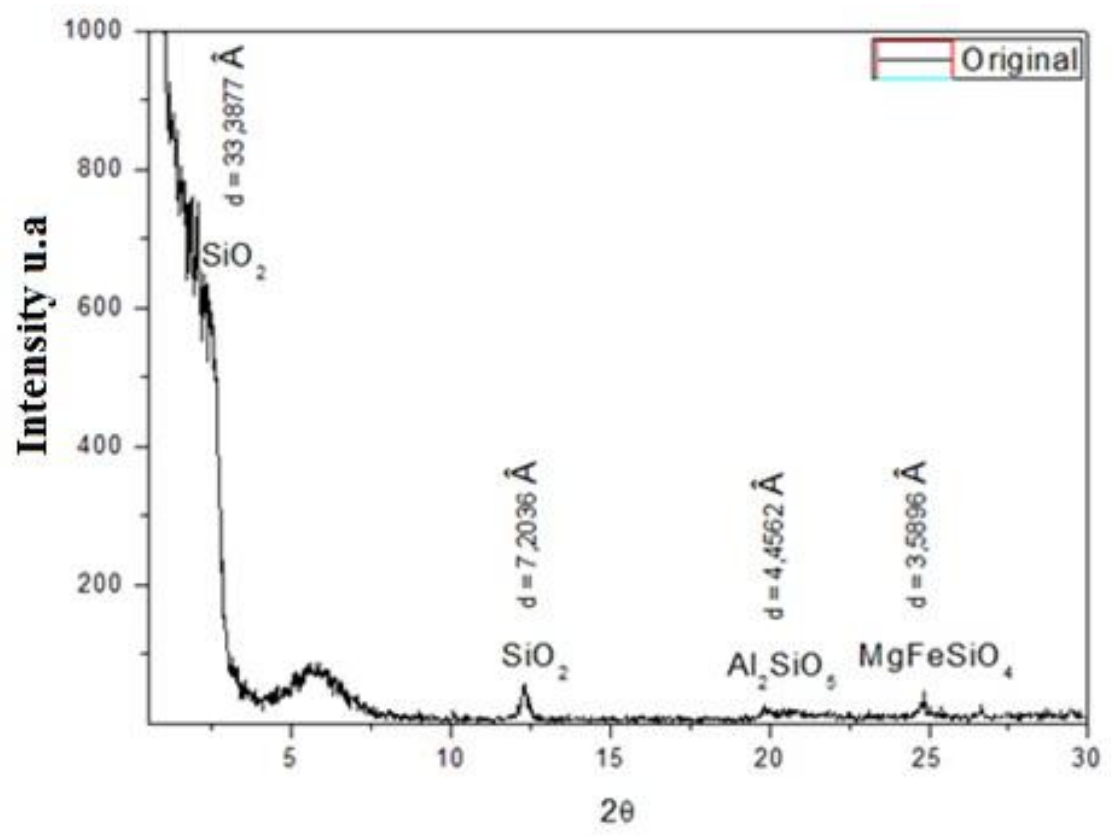

Figure 1. XRD of the original clay.

$7.2036 \AA$ at positions $2.64^{\circ}$ and $12.28^{\circ}$, respectively. Aluminum silicate at position $19.92^{\circ}$ with interplanar distance of $4.4562 \AA$ and olivine at position $24.8^{\circ}$ with $3.5896 \AA$ have also been identified.

Similar data for the organophilized clay samples are shown in Table 3, and indicate that there was practically no increase in the interplanar distance for the same angles when compared with the original clay. This is possibly due to the fact that the surfactant molecules could not be adsorbed among the layers of the mineral clay.

For SCO solutions $30 \%$ lower than the c.m.c., however, the interplanar distance changed, and

Table 3. Interplanar distances for clay samples obtained by X-ray diffraction.

\begin{tabular}{|c|c|c|c|c|c|c|c|c|}
\hline Clay Sample & $\theta\left({ }^{\circ}\right)$ & d / A & $\theta\left({ }^{\circ}\right)$ & d / A & $\theta\left({ }^{\circ}\right)$ & d / A & $\theta\left(^{\circ}\right)$ & d / A \\
\hline Original & 2.64 & 33.3887 & 12.28 & 7.2036 & 19.92 & 4.4562 & 24.80 & 3.5896 \\
\hline $\begin{array}{l}\text { Treated with SCO } 30 \% \text { higher than } \\
\text { c.m.c. }\end{array}$ & 2.53 & 34.8568 & 12.39 & 7.1409 & 19.89 & 4.4623 & 24.92 & 3.5720 \\
\hline Treated with SCO at c.m.c. & 2.67 & 33.0584 & 12.38 & 7.1476 & 19.79 & 4.4845 & 24.79 & 3.5916 \\
\hline $\begin{array}{l}\text { Treated with SCO } 30 \% \text { lower than } \\
\text { c.m.c. }\end{array}$ & ----- & ----- & 12.37 & 7.1535 & 19.96 & 4.4479 & 24.68 & 3.5810 \\
\hline $\begin{array}{l}\text { Treated with } \mathrm{CTAB} 30 \% \text { higher than } \\
\text { c.m.c. }\end{array}$ & 2.65 & 33.2898 & 12.27 & 7.2105 & 19.86 & 4.4692 & ----- & ----- \\
\hline Treated with CTAB at c.m.c & 2.54 & 34.6786 & 12.92 & 7.2010 & 20.10 & 4.4178 & 24.86 & 3.5813 \\
\hline $\begin{array}{l}\text { Treated with CTAB } 30 \% \text { lower than } \\
\text { c.m.c. }\end{array}$ & 2.48 & 35.5725 & 12.30 & 7.1954 & 19.91 & 4.4591 & 24.85 & 3.5827 \\
\hline $\begin{array}{l}\text { Treated with UTM } 150 \text { 30\% higher than } \\
\text { c.m.c. }\end{array}$ & 2.60 & 33.9265 & 12.31 & 7.1854 & 19.92 & 4.4567 & 24.77 & 3.5931 \\
\hline Treated with UTM 150 at c.m.c & 2.61 & 33.8165 & 12.29 & 7.1988 & 19.79 & 4.4857 & 24.82 & 3.5866 \\
\hline $\begin{array}{l}\text { Treated with UTM } 15030 \% \text { lower than } \\
\text { c.m.c. }\end{array}$ & 2.55 & 34.5251 & 12.52 & 7.1651 & 19.88 & 4.4654 & 24.81 & 3.5885 \\
\hline
\end{tabular}


Table 4. Contact angles of clay samples.

\begin{tabular}{|c|c|c|c|c|c|c|}
\hline Clay sample & $\begin{array}{c}\theta_{1} \\
\text { (water) }\end{array}$ & $\begin{array}{c}\theta_{2} \\
\text { (water) }\end{array}$ & Average & Deviation & $\begin{array}{c}\theta_{1} \\
\text { (n-paraffin) }\end{array}$ & $\begin{array}{c}\theta_{2} \\
\text { (n-paraffin) }\end{array}$ \\
\hline Original & 17.7 & 20.2 & 18.9 & 1.76 & 0 & 0 \\
\hline $\begin{array}{l}\text { Treated with SCO } 30 \% \text { higher } \\
\text { than c.m.c. }\end{array}$ & 35.9 & 38.6 & 37.2 & 1.90 & 21.8 & 26.2 \\
\hline Treated with SCO at c.m.c. & 39.7 & 33.8 & 36.7 & 4.17 & 17.5 & 22.0 \\
\hline $\begin{array}{l}\text { Treated with SCO } 30 \% \text { lower } \\
\text { than c.m.c. }\end{array}$ & 37.3 & 39.1 & 38.2 & 1.27 & 17.6 & 23.9 \\
\hline $\begin{array}{l}\text { Treated with CTAB } 30 \% \text { higher } \\
\text { than c.m.c. }\end{array}$ & 38.7 & 43.9 & 41.3 & 3.67 & 0 & 0 \\
\hline Treated with CTAB at c.m.c & 42.2 & 38.9 & 40.5 & 2.33 & 0 & 0 \\
\hline $\begin{array}{l}\text { Treated with CTAB } 30 \% \text { lower } \\
\text { than c.m.c. }\end{array}$ & 37.3 & 31.0 & 34.1 & 4.45 & 0 & 0 \\
\hline $\begin{array}{l}\text { Treated with UTM } 150 \quad 30 \% \\
\text { higher than c.m.c. }\end{array}$ & 30.5 & 22.8 & 26.2 & 5.44 & 0 & 0 \\
\hline Treated with UTM 150 at c.m.c & 28.7 & 24.3 & 26.5 & 3.11 & 0 & 0 \\
\hline $\begin{array}{l}\text { Treated with UTM } 150 \quad 30 \% \\
\text { lower than c.m.c. }\end{array}$ & 35.7 & 22.7 & 29.2 & 9.19 & 0 & 0 \\
\hline
\end{tabular}

one of the peaks at approximately $2.64^{\circ}$ could not be detected when compared with the original clay. In this case, the surfactant caused a change in the crystalline phase at this position. It is possible that, in spite of its difficulty in adsorbing on the clay at higher concentrations, as suggested by the surface tension data, the low concentration favors SCO in this case to alter one of the phases, so it adsorbs more easily on the clay surface. CTAB and UTM 150 , on the other hand, promote little increase in the basal spacing. Since the clay used in the organophilization is calcic, its cationic exchange capacity is actually weaker if compared with sodium bentonite's one. Calcium ions can be found among the layers of the mineral and, being divalent, they can induce more intense attractive phenomena among the layers, thereby impairing the organophilization process. As a result, narrower layers are formed because of calcium ions and net forces in the structure, which can justify the fact that the capacity of the ions of the mineral clay to be replaced with surfactant molecules is diminished.

Aiming to verify the potential of the organophilized clay to change its wettability to a more oil-wettable state, contact angle measurements were performed with water and $n$ paraffin on original and modified clay samples. Table 4 presents the acquired data.
Table 4 indicates that the original bentonite has mixed wettablity, that is, it can be both oil- and water-wettable. However, one can observe that the oil-wetting feature was favored as suggested by the value of the contact angle with water when surfactants are used. The chemical structure of the surfactant molecules affects greatly the wettability of bentonite. It can be seen that CTAB and UTM 150 provided better results than SCO. Cationic and nonionic surfactants could modify the wettability of bentonite more intensely with stronger interactions on the negatively charged surface of the clay. Therefore, the polar moiety of the surfactant molecule is oriented toward the clay layers and its nonpolar part remains in contact with the oil at the fluid-clay interface. This renders the bentonite a more oil-wettable surface. Particularly, with regards to UTM 150, since a significant adsorption ability was observed. Although its molecules did not show a free charge and weaker van der Waals chemical interactions were established in the solution as a result of the polarization phenomena inflicted on the surfactant molecule by the net surface charge of the clay.

Anionic SCO could not provide satisfactory results, since the corresponding contact angles indicated that the wettability of the organophilized clay was altered. From the assays carried out with the oil phase, one can observe that the angle increased when compared with the assays 
involving the original clay. This is an indication that it is less oil-wettable possibly due to the anionic character of the surfactant. Predominantly repulsive forces are generated between its molecules and the surface of the clay. Therefore, it could be verified that the potential for better wettability modification follows the order CTAB > UTM 150 > SCO.

\section{CONCLUSIONS}

This work demonstrates that surfactants CTAB and UTM150 can be more adsorbed strongly on the surface of bentonite at any concentration, based on the high surface tension of the filtrates obtained after interaction with the clay. Anionic SCO was also investigated but the results are satisfactory only when the surfactant is used at a concentration $30 \%$ lower than its critical micelle concentration, so as to minimize interactions with the negativelycharged surface of the clay, which impairs adsorption due to charge repulsions. XRD assays indicated that the basal spacing of the clay did not change much because of the low cationic exchange capacity of the clay. The contact angle data suggest that the organophilized clay shows mixed wettability, although the oil-wetting feature is more pronounced. Regardless of the surfactant concentration used, the results indicate that changes were effected in the affinity of the clay with oil, rendering it more hydrophobic. The organophilization capacity of the surfactants follows the order SCO < UTM $150<$ CTAB. Therefore, the chemical modification of bentonitic clay with CTAB surfactant was more efficient. This enables the use of such clay as a viscosifying agent in the composition of oil-based drilling fluids. However, it would be interesting to study the UTM 150 surfactant at concentrations much above the critical micelle concentration (c.m.c.) because, according to Sánchez-Martín et al. (2008), nonionic surfactants can be more efficient when used in high concentrations, which would render the use of UTM 150 more advantageous. Plus, the CTAB surfactant is very expensive, which can impair some of its technological applications.

\section{ACKNOWLEDGEMENTS}

The authors are grateful to the Brazilian agencies ANP - PRH - PB 221 for the financial support.

\section{REFERENCES}

Bourgoyne Jr, A. T.; Millheim, K.K.; Chenevert, M. E.; Young Jr, F. S. Applied Drilling Engineering. Texas: Society of Petroleum Engineers Editor, 1991. $502 \mathrm{p}$.

Caenn, R.; Chillingar, G. V. Drilling fluids: state of the art. Journal of Petroleum Science and Enginnering, v.14, p. 221-230, 1996. https://doi.org/10.1016/0920-4105(95)00051-8

Melton, H.R.; Smith, J.P.; Mairs, H.L.; Bernier, R.F.; Garland, E.; Glickman, A.H.; Jones, F.V.; Ray, J.P.; Thomas, D.; Campbell, J.A. Environmental aspects of the use and disposal of non aqueous drilling fluids associated with offshore oil \& gas operations. United Kingdom: International Association of Oil \& Gas Producers, 2003, 106p.

Ouellet - Plamondon, C.M.; Stasiak, J.; AlTabbaa, A. The effect of cationic, non-ionic and amphiphilic surfactants on the intercalation of bentonite. Colloids and Surfaces A: Physicochem. Eng. Aspects, v.444, p. 330-337, 2014. https://doi.org/10.1016/i.colsurfa.2013.12.032

Parolo, M.E.; Pettinari, G.R.; Musso, T.B.; Sánchez-Izquierdo, G.P.; Fernández, L.G. Characterization of organo-modified bentonite sorbents: The effect of modification conditions on adsorption performance. Applied Surface Science, v.320, p. 356-363, 2014.

https://doi.org/10.1016/i.apsusc.2014.09.105

Sánchez-Martín, M.J.; Dorado, M.C.; Del Hoyo, C.; Rodríguez-Cruz, S.M. Influence of clay mineral structure and surfactant nature on the adsorption capacity of surfactants by clays. Journal of Hazardous Materials, v.150, p. 115-123, 2008. https://doi.org/10.1016/j.jhazmat.2007.04.093

Silva, I.A., Sousa, F.K.A., Menezes, R.R., Neves, G.A., Santana, L.N.L., Ferreira, H.C. Modification of bentonites with nonionic surfactants for use in organic-based drilling fluids. Applied Clay Science, v.95, p. 371-377, 2014.

https://doi.org/10.1016/i.clay.2014.04.021 